DOI: https://doi.org/10.46667/renbio.v13i1.312

\title{
O ensino de zoologia em escolas da Superintendência Regional de Ensino de Caratinga/Minas Gerais
}

\author{
Zoology teaching in schools of the Regional Teaching Superintendence of \\ Caratinga / Minas Gerais
}

Natália Siqueira Moreira ${ }^{1}$; Ione Maria de Matos $^{2}$

\begin{abstract}
Resumo
Objetivou-se analisar as metodologias e recursos didáticos utilizados no ensino de Zoologia em escolas da SRE de Caratinga e elaborar propostas que colaborem para o processo ensino-aprendizagem. Questionários semiestruturados foram aplicados a 28 professores que lecionam Ciências e/ou Biologia no sétimo e segundo anos dos ensinos fundamental e médio respectivamente, em 29 escolas estaduais de 7 municípios. A maior parte desses professores realizam o ensino pautado na memorização do conteúdo, utilizam principalmente o livro didático, não fazem relação eco evolutiva das espécies animais, faltam espaços para a realização de atividades práticas e recursos metodológicos. Propostas foram elaboradas e compiladas em um caderno de sugestões com estratégias para o ensino de Zoologia e disponibilizado aos professores e a SRE de Caratinga.
\end{abstract}

Palavras-chave: Ensino de Zoologia; Ensino Fundamental e Médio; Metodologias; Professores.

\begin{abstract}
The objective was to analyze the methodologies and didactic resources used in the teaching of Zoology in schools of the SRE of Caratinga and to elaborate proposals that collaborate for the teaching-learning process. Semi-structured questionnaires were applied to 28 teachers who teach Science and / or Biology in the seventh and second years of primary and secondary education, respectively, in 29 state schools in 7 municipalities. Most of these teachers carry out teaching based on memorizing the content, they mainly use the textbook, they do not relate to the evolutionary echo of animal species, there is a lack of spaces for carrying out practical activities and methodological resources. Proposals were prepared and compiled in a book of suggestions with strategies for teaching Zoology and made available to teachers and the SRE of Caratinga.
\end{abstract}

Keywords: Zoology teaching; Elementary and high school; Methodologies; Teachers.

\footnotetext{
${ }^{1}$ Mestrado Profissional em Ensino de Biologia - Universidade Federal de Juiz de Fora (UFJF). Campus avançado de Governador Valadares, MG - Brasil. Professora Efetiva de Biologia - Escola Estadual "Alberto Azevedo"; Professora Efetiva de Ciências - Escola Municipal "Barão do Rio Branco". Inhapim, MG - Brasil. E-mail: natysm@gmail.com

${ }^{2}$ Doutora em Ciências Biológicas - Universidade Federal de Minas Gerais (UFMG), Belo Horizonte, MG Brasil. Professora permanente - Universidade Federal de Juiz de Fora (UFJF), Campus avançado de Governador Valadares, MG - Brasil. E-mail: mione4615@gmail.com
}

Submetido em: 20/04/2020 - Aceito em: 17/06/2020 
DOI: https://doi.org/10.46667/renbio.v13i1.312

\section{Introdução}

Segundo o INEP (2010) o ensino de Ciências deve ser pautado no letramento científico, que se refere tanto à compreensão de conceitos científicos quanto à capacidade de aplicar esses conceitos e pensar sob uma perspectiva científica. Também fazem parte do conceito de letramento científico: a) a compreensão das características que diferenciam a Ciência como uma forma de conhecimento e investigação; b) a consciência de como a Ciência e a tecnologia moldam nosso meio material, cultural e intelectual e c) o interesse em engajar-se em questões científicas, como cidadão crítico capaz de compreender e tomar decisões sobre o mundo natural e as mudanças nele ocorridas. Neste contexto é importante o uso de metodologias na perspectiva de ensino-aprendizagem, bem como, são necessárias maiores reflexões em alguns ramos no ensino de Ciências e Biologia no Brasil (SANTOS e FACHÍN-TERÁN, 2013; VASCONCELOS e SOUTO, 2003).

A abordagem do conteúdo de Zoologia geralmente é ministrada de maneira pouco contextualizada e fragmentada, persistindo com a memorização de conteúdo e fundamentada em aulas que utilizam apenas o livro didático, privilegiando aspectos morfofisiológicos em detrimento dos aspectos evolutivos (SANTOS e FACHÍN-TERÁN, 2009; DE AZEVEDO, 2019). Aliado a esses fatores, há falta de espaços adequados, de recursos didáticos alternativos, tempo reduzido do professor para planejar e executar suas atividades acadêmicas em sala de aula e formação acadêmica deficiente do professor em relação à realidade de ensino (AZEVEDO, OLIVEIRA e LIMA, 2016; SANTOS e FACHÍN-TERÁN, 2009).

Algumas propostas direcionadas ao ensino de Zoologia têm sido sugeridas, como por exemplo, aplicação de questionário a alunos e professores, construção de cladograma e atividades investigativas (LOPES et al.,2007; FERREIRA et al., 2008; DIAS e SESSA, 2017), entretanto, NEVES e SCHWANTES 2019, consideram que tais propostas apresentam algumas limitações, tais como, apresentação de aulas teóricas antes das aulas práticas o que restringe a autonomia dos estudantes; ausência de relações com a Anatomia, Ecologia e Evolução dos animais e apresentação inadequada de resultados e discussões sobre a aprendizagem dos estudantes.

O uso de metodologias investigativas, demonstrativas, expositivas dialogadas e lúdicas tornam as aulas, dinâmicas, interativas e motivadoras, bem como facilitam a aprendizagem pelos alunos (SANTOS e GUIMARÃES, 2010; JÚNIOR, 2013). Recentemente, foi demonstrado que a construção de tirinhas em quadrinhos, com enfoque nas relações ambientais entre humanos e animais estigmatizados pela população, é um recurso viável, recomendado e possível de fomentar debates, o que permite aos educandos se tornarem mais ativos durante a atividade (SANTANA et. al., 2020). No cotidiano da nova geração de alunos, o acesso a tecnologias e informação é uma realidade inquestionável e para se ter resultados satisfatórios com essa geração é necessário utilizar novas metodologias e estratégias diversificadas para não perder o foco do aprendizado (ANTUNES, 2002). 
DOI: https://doi.org/10.46667/renbio.v13i1.312

Diante dessa realidade o presente estudo foi elaborado visando refletir, investigar e descrever como é realizado o ensino de Zoologia para os alunos do Ensino Fundamental e Ensino Médio em algumas escolas da Superintendência Regional de Ensino (SRE) de Caratinga e a partir dos resultados obtidos, foi elaborado um caderno de estratégias para o referido ensino.

Entendemos que no trabalho docente, a análise das metodologias e recursos didáticos são ferramentas que oferecem informações sobre o processo ensino-aprendizagem e facilitam na compreensão da necessidade de reorientar as metodologias rotineiramente utilizadas. Desse modo, o presente artigo pretende responder as seguintes questões: Qual o perfil dos professores de Zoologia na SRE de Caratinga? Que materiais didáticos eles utilizam? Qual a visão deles sobre a infraestrutura da escola para o ensino de Zoologia? Qual a importância da elaboração de sugestões para auxiliar nesse ensino? Os professores têm interesse em propostas pedagógicas para o ensino de Zoologia?

\section{Um Breve Histórico da Superintendência Regional de Caratinga}

A Superintendência Regional de Ensino de Caratinga foi instalada no dia 06 de março de 1971, pelo Decreto 12880 de 04/08/1970, assinado pelo Governador do Estado, Sr. Israel Pinheiro da Silva. A missão da SRE Caratinga é desenvolver e coordenar políticas públicas de educação básica, inclusivas e de qualidade, garantindo plenas condições de funcionamento da rede pública, em especial da rede estadual, promovendo a formação integral dos estudantes, com vistas ao exercício da cidadania e à inserção no mundo do trabalho. A jurisdição da SRE de Caratinga compõe-se de 24 municípios, sendo eles Alvarenga, Bom Jesus do Galho, Bugre, Caratinga, Córrego Novo, Dom Cavati, Entre Folhas, Iapu, Imbé de Minas, Inhapim, Ipaba, Ipanema, Piedade de Caratinga, Pingo D'Água, Pocrane, Santa Bárbara do Leste, Santa Rita de Minas, São Domingos das Dores, São João do Oriente, São Sebastião do Anta, Taparuba, Tarumirim, Ubaporanga, Vargem Alegre. Atualmente a SRE presta assessoria a 89 escolas estaduais, 228 municipais, 9 particulares e 8 APAES. Sendo que dentre as 89 escolas estaduais, 53 atendem a modalidade de Ensino Médio. Este trabalho é pioneiro no município e vai ao encontro da visão de futuro da SRE Caratinga que é ser referência pela excelência em educação básica, com qualidade e equidade. 
DOI: https://doi.org/10.46667/renbio.v13i1.312

\section{Metodologia}

Para responder às nossas indagações, a coleta de dados foi realizada por meio de questionário semiestruturado com perguntas abertas e fechadas conforme adaptado da dissertação de SANTOS (2010) sobre o ensino de Zoologia em Manaus/AM. O modelo não foi validado, mas o consideramos pertinente para a coleta de dados, uma vez que já havia sido utilizado e aprovado na defesa de mestrado. Foram ainda abordados eixos temáticos sobre o perfil e a formação profissional do professor; as metodologias e estratégias de ensino; a relação do conteúdo ministrado com o livro didático e fauna mineira (adaptação para este trabalho); que contemplam o objetivo desta investigação. Nosso estudo, caracterizou-se como uma Pesquisa Descritiva de natureza quali-quantitativa e com caráter de levantamento, conforme Gil (2008), devidamente aprovado pelo Comitê de Ética do Instituto de Ciências Biológicas da Universidade Federal de Juiz de Fora - sob o Parecer de número 2.667.218.

A pesquisa foi realizada em 29 escolas estaduais de 7 municípios da SRE de Caratinga, sendo eles Dom Cavati, Inhapim, São Domingos das Dores, São Sebastião do Anta, Tarumirim, Ubaporanga e Vargem Alegre, que englobam a modalidade de Ensino Fundamental e Médio. As escolas foram escolhidas por serem públicas e pela proximidade da localização geográfica entre os municípios. Os critérios de inclusão para participação na pesquisa foram: ser professor de Ciências e Biologia das Escolas Estaduais da Superintendência de Caratinga, e ministrar aulas para o $7^{\circ}$ ano do Ensino Fundamental e para o $2^{\circ}$ ano do Ensino Médio, pois o conteúdo de Zoologia é ministrado nessas séries. Os critérios de exclusão consistiam de professores que se recusassem a assinar o Termo de Consentimento Livre e Esclarecido (TCLE). Os professores de Ciências e Biologia que lecionam para o $7^{\circ}$ ano do Ensino Fundamental e $2^{\circ}$ ano do Ensino Médio que trabalham diretamente com o conteúdo de Zoologia das escolas públicas daqueles municípios citados acima foram convidados a participar da pesquisa, e após consentimento, todos assinaram o TCLE.

O período da pesquisa estendeu-se de novembro de 2017 a junho de 2019, com envio de e-mails e período de visitação nas escolas, de agosto do ano de 2018 a março de 2019. Os questionários foram disponibilizados para todos os professores por e-mail, e/ou por visitação.

As análises dos dados das perguntas fechadas foram realizadas através da porcentagem absoluta e relativa (CRESPO, 2009). Algumas apresentavam espaço para comentários não obrigatórios, e quando preenchido foi considerada questão fechada-aberta. Já as perguntas abertas foram analisadas qualitativamente através da análise de conteúdo (BARDIN, 2009; CAMPOS, 2004) onde procurou-se à similaridade entre as respostas o que permitiu a organização das mesmas possibilitando assim a interpretação e as inferências das respostas dadas pelos professores. 
DOI: https://doi.org/10.46667/renbio.v13i1.312

As sugestões de metodologias foram elaboradas após extensas pesquisas em diversos sites, artigos científicos, dissertações e enfatizaram propostas que pudessem ser realizadas em sala de aula e trouxessem uma abordagem investigativa, lúdica e focada na realidade do aluno.

\section{Resultados}

\section{1 Identificação do Perfil do Professor de Ciências/Biologia}

Responderam ao questionário 28 professores, sendo que a maioria são concursados. Houve predominância do sexo feminino (71,42\%). A faixa etária variou de 20 a 50 anos, sobressaindo a faixa entre 30 e 45 anos. A maior parte dos professores possui de 11 a 15 anos de experiência em magistério na SRE, seguidos daqueles que tem menos de 5 anos e dos que têm de 5 a 10 anos de experiência. Em relação a formação dos professores, todos possuíam nível superior com graduação em Licenciatura Plena em Ciências Biológicas. A maioria dos professores acumula as disciplinas de Ciências e Biologia na escola que lecionam, e 25\% relataram trabalhar somente com Ciências ou somente Biologia.

Sobre a formação inicial dos professores, $100 \%$ dos profissionais admitiram terem cursado disciplinas que envolviam Zoologia e justificaram estarem preparados para este conteúdo escolhendo entre duas categorias de concepções: Concepção 1, grupo de professores que justificam a preparação do ensino por meio do conteúdo científico e Concepção 2, grupo de professores que discernem o conteúdo científico do conteúdo didático-pedagógico (tabela 1). Dos professores que comentaram sua escolha, a maioria se encontra na Concepção 1, pois 89,3\% acreditam que as disciplinas específicas de Zoologia e aulas práticas que cursaram ao longo da formação inicial, os tornaram aptos a lecionar Zoologia para o Ensino Fundamental e Médio. Na Concepção 2, onde se encontra a minoria dos professores que comentaram, 10,7\% afirmaram que não houve preparação específica para a prática pedagógica do ensino de Zoologia, ocorrendo apenas a disciplina de Didática Geral e as disciplinas de conhecimento científico acerca da Zoologia, com enfoque apenas no ensino superior. Abaixo estão as transcrições de alguns professores sobre esse questionamento:

"No meu curso havia disciplinas especificas de Zoologia, como Zoologia I e II, Zoologia comparada e Zoologia de invertebrados, e acredito que este conhecimento me preparou para lecionar Zoologia” (professor número 1).

"As aulas práticas e atividades de campo e coleta de animais juntamente com o conteúdo teórico ministrado me capacitaram para ensinar Zoologia” (professor número 2). 
DOI: https://doi.org/10.46667/renbio.v13i1.312

Tabela 1: As concepções sobre o conteúdo científico em função do preparo para o Ensino de Zoologia

\begin{tabular}{l|c|c|c|c}
\hline \multirow{2}{*}{\begin{tabular}{l} 
Concepções \\
\cline { 2 - 5 }
\end{tabular}} & \multicolumn{2}{|c|}{$\begin{array}{c}\text { Professores de Ciências } \\
\text { e/ou Biologia }\end{array}$} & \multicolumn{2}{c}{$\begin{array}{c}\text { Professores de Ciências } \\
\text { e/ou Biologia que } \\
\text { comentaram a sua resposta }\end{array}$} \\
\cline { 2 - 5 } & $\mathrm{N}$ & $\%$ & $\mathrm{~N}$ & $\%$ \\
\hline $\begin{array}{l}\text { Concepção 1: Grupo de } \\
\text { professores que justificam a } \\
\text { preparação do ensino por } \\
\text { meio do conteúdo científico. }\end{array}$ & 25 & 89,3 & 10 & $35,7 \%$ \\
\hline $\begin{array}{l}\text { Concepção 2: Grupo de } \\
\text { professores que discernem o } \\
\text { conteúdo científico do } \\
\text { conteúdo didático- } \\
\text { pedagógico }\end{array}$ & 3 & 10,7 & 2 & $7,14 \%$ \\
\hline \begin{tabular}{l} 
Total \\
\hline
\end{tabular} & 28 & 100 & 12 & 42,86 \\
\hline
\end{tabular}

4. 2 Recursos didáticos e materiais didáticos para o Ensino de Zoologia na SRE de Caratinga

A maioria dos professores relatou não existir qualquer material didático na sua escola, bem como afirmaram que as instalações físicas de suas respectivas escolas não propiciam o ensino de Zoologia, pois faltam laboratórios ou áreas que se destinem a esse objetivo, em contrapartida, 39,3\% apontaram que em suas escolas existem instalações físicas (laboratórios) que propiciam o ensino. O termo material didático aqui empregado compreende materiais como microscópios, lupas, coleções zoológicas, diferindo de materiais como o livro didático, projetores, computadores, televisões. Outro ponto levantado pelos professores é o espaço físico dos laboratórios, pois, o número de alunos por turma (geralmente 35 alunos no Ensino Fundamental e 45 no Ensino Médio) excede à capacidade dos mesmos, inviabilizando sua utilização. Tais apontamentos são evidenciados nas transcrições dos professores abaixo:

“Falta espaço físico como apoio a teoria” (professor número 3).

"A escola possui o espaço, porém falta espécimes para utilização em aulas práticas" (professor número 4).

"As turmas geralmente são muito cheias, o que inviabiliza o uso do laboratório ou de qualquer atividade prática” (professor número 5). 
DOI: https://doi.org/10.46667/renbio.v13i1.312

Em muitas destas escolas visitadas, foi verificado que existiam laboratórios e que eles foram abandonados, sendo destinados a sala de recursos (para alunos com necessidades especiais), sala de mídia visual, sala para guardar materiais diversos. Tais informações são similares aos dados reportados pela Organização para a Cooperação e Desenvolvimento Econômico (OCDE) entidade que coordena o Programa Internacional de Avaliação de Estudantes (PISA), pois, relatam que $90 \%$ das escolas brasileiras não possuem estrutura física e material adequado para o Ensino de Ciências (WAISELFISZ, 2009).

Sobre o livro didático, 64,3\% $(\mathrm{N}=18)$ dos professores o aprovam. Ao analisar as respostas dos professores que aprovaram, os principais argumentos foram que os livros trazem textos objetivos e com muitas ilustrações e que são compatíveis com o Ensino Básico. Já o argumento dos professores que reprovaram foi principalmente que os livros se limitam a morfofisiologia e classificação dos animais, e que predomina o conhecimento acadêmico, sendo os textos fragmentados e desatualizados.

\subsection{Principais metodologias utilizadas pelos professores no ensino de Zoologia}

Em relação aos questionamentos sobre os métodos de ensino de Zoologia, percebeu-se que os professores associaram de forma equivocada, metodologias com estratégias de ensino. Assim as respostas foram classificadas em quatro categorias de estratégias (Tabela 2), sendo as aulas expositivas simples e dialogada como as mais frequentemente usadas, e em segundo lugar a aula expositiva com uso de vídeos e projeções. Ao analisar as estratégias utilizadas percebemos que a maioria dos professores utiliza a forma tradicional de ensino, centralizada no professor. Sobre a realização de aulas práticas, metade afirma ministrar e metade afirmam o contrário. Os professores que não realizam as aulas práticas justificam entre outras coisas; a falta de laboratório, materiais e espaço inadequados para tal fim. Já os professores que realizam tal prática de ensino, mesmo a escola não possuindo laboratório, alegam utilizar o espaço da própria sala de aula, ou espaços em torno da escola para demonstrações ou experimentos relacionados ao conteúdo zoológico, bem como utilização de vídeos e apresentações de seminários.

Tabela 2: Porcentagem relativa das estratégias de Ensino utilizada pelos professores para o ensino de Zoologia

\begin{tabular}{l|l|l}
\hline Estratégias de Ensino & N & \% \\
\hline A. Aula expositiva simples e dialogada & $\mathbf{2 8}$ & $\mathbf{1 0 0 \%}$ \\
\hline B. Aula expositiva com vídeos e projeção & $\mathbf{1 8}$ & $\mathbf{6 4 , 3 \%}$ \\
\hline C. Jogos e aplicativos & $\mathbf{4}$ & $\mathbf{2 2 , 2 \%}$ \\
\hline D. Trabalho de campo & $\mathbf{4}$ & $\mathbf{2 2 , 2 \%}$ \\
\hline
\end{tabular}


DOI: https://doi.org/10.46667/renbio.v13i1.312

A tabela 3 mostra os apontamentos dos professores em relação a ênfase do conteúdo de Zoologia nos livros didáticos, para o conteúdo de vertebrados e invertebrados, a morfofisiologia e a relação dos animais com doenças e zoonoses.

Tabela 3: Porcentagem relativa sobre a ênfase dos conteúdos zoológicos no $7^{\circ}$ e $2^{\circ}$ ano.

\begin{tabular}{c|c|c|c|c}
\hline \multirow{2}{*}{ Ênfases } & \multicolumn{2}{|c|}{ Vertebrados } & \multicolumn{2}{c}{ Invertebrados } \\
\cline { 2 - 5 } & $\mathrm{N}$ & $\%$ & $\mathrm{~N}$ & $\%$ \\
\hline Morfofisiologia & 28 & $100 \%$ & 28 & $100 \%$ \\
\hline Contextualização da Ecologia e Evolução & 5 & $17,86 \%$ & 3 & $10,71 \%$ \\
\hline Relação com zoonoses & 19 & $67,85 \%$ & 28 & $100 \%$ \\
\hline
\end{tabular}

Observação: informações coletadas numa questão de múltiplas escolhas, podendo marcar mais de uma opção de resposta.

Quanto aos animais que chamam mais atenção e despertam o interesse dos discentes (Tabela 4), os animais peçonhentos ou venenosos foram os mais apontados pelos professores, e em menor número os vermes e anfíbios.

Tabela 4: Nomes dos animais que os alunos mais gostam na opinião dos professores.

\begin{tabular}{l|c|c}
\multicolumn{1}{c|}{ Grupo de animais } & \multicolumn{2}{c}{$\begin{array}{c}\text { Animais que os alunos mais } \\
\text { gostam. }\end{array}$} \\
\cline { 2 - 3 } & $\mathrm{N}$ & $\%$ \\
\hline Animais peçonhentos e venenosos & 14 & $50 \%$ \\
\hline Anfíbios & 3 & 10,7 \\
\hline Vermes & 1 & 3,6 \\
\hline Vertebrados & 10 & 35,7 \\
\hline Total & 28 & $100 \%$ \\
\hline
\end{tabular}

Com respeito ao uso de animais regionais (Mata Atlântica e Cerrado) nas aulas de Zoologia, 22 professores $(78,57 \%)$ confirmaram a sua utilização durante as aulas e 6 professores $(21,42 \%)$ negaram sua utilização. Os nomes científicos não foram inseridos devido ao fato de a maioria dos professores desconhecerem as características taxonômicas que poderiam ajudar na identificação dos animais. A tabela 5 listam as classes e grupos de animais que são abordados com mais frequência pelos professores nas aulas de Zoologia. 
DOI: https://doi.org/10.46667/renbio.v13i1.312

Tabela 5: Listagem de animais e grupo de animais apresentada pelos professores nas aulas de Zoologia

\begin{tabular}{l|l}
\hline \multicolumn{1}{c|}{ Classe } & \multicolumn{1}{c}{ Grupo de animais } \\
\hline Mamíferos & $\begin{array}{l}\text { onça, gambá, lobo-guará, tamanduá - bandeira, } \\
\text { veado, capivara, muriqui, mico-leão dourado, } \\
\text { gato do mato, tatu }\end{array}$ \\
\hline Aves & $\begin{array}{l}\text { canário, seriema, garça, tucano, arara azul, } \\
\text { papagaios. }\end{array}$ \\
\hline Répteis & lagarto, jacarés, cobra, cobra-coral, jabuti. \\
\hline Anfíbios & sapos, rãs e pererecas. \\
\hline Peixes & tilápia. \\
\hline Invertebrados & $\begin{array}{l}\text { escorpião, aranha-marrom, borboletas, } \\
\text { formigas, minhocas, moscas e abelhas. }\end{array}$ \\
\hline
\end{tabular}

No tocante às formas de avaliação do aprendizado do estudante, constatou-se que é feita, mais frequentemente, através de métodos tradicionais, ou seja, realização de provas escritas individuais ( $\mathrm{N}=28,100 \%)$. A auto avaliação pelos professores do Ensino de Zoologia foi realizada em uma escala de valores: ruim, regular, bom e excelente. Todos os professores entrevistados consideraram o ensino bom ( $\mathrm{N}=28,100 \%)$.

As duas principais sugestões para a melhoria do ensino de Zoologia apresentadas pelos professores de Ciências e Biologia, foram a construção de Laboratório $(67,85 \%)$ e a aquisição de materiais didáticos $(71,42 \%)$, seguida do uso de espaço não-formais (saídas de campo) $(14,28 \%)$, formação continuada dos professores $(10,71 \%)$ e escolha criteriosa do livro didático $(3,57 \%)$ (Figura 1).

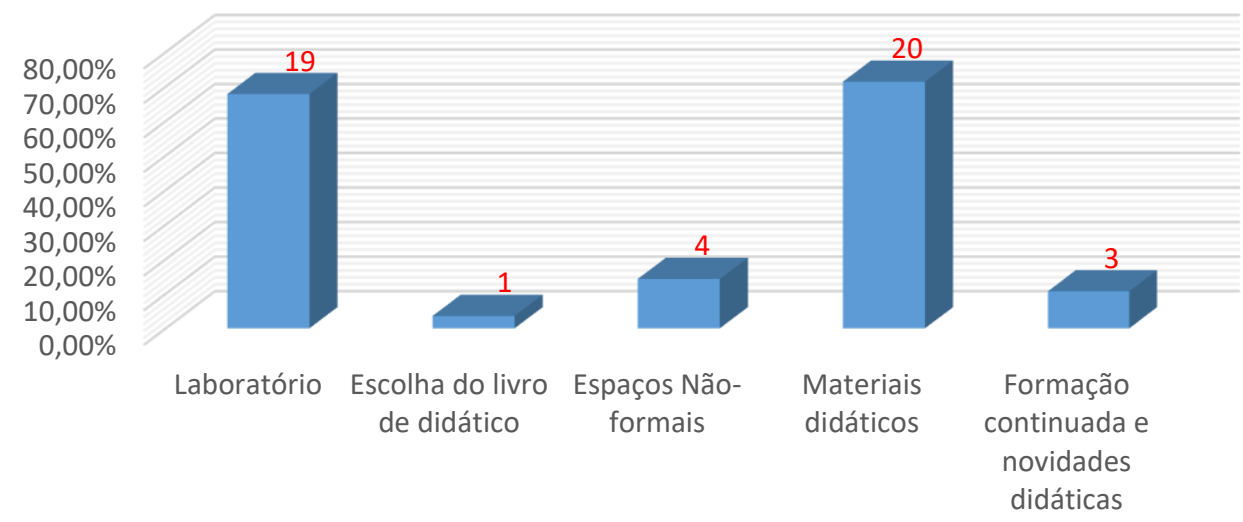

Figura 1: Porcentagem relativa das sugestões feitas pelos profissionais da educação para a melhoria do Ensino de Zoologia. 
DOI: https://doi.org/10.46667/renbio.v13i1.312

\section{Sugestões de Estratégias para o Ensino de Zoologia}

Após os resultados apresentados neste trabalho procedemos com a confecção de um caderno contendo 8 propostas de estratégias para o ensino de Zoologia na SRE de Caratinga, bem como, tutoriais para confecção e utilização de cada proposta. Abaixo listamos algumas sugestões que estão no caderno:

- BINGO DE PALAVRAS - O bingo de palavras pode ser utilizado de duas formas:

$\left.1^{a}\right)$ Metodologia ativa: anteriormente ao dia em que o bingo for utilizado, pedir que os alunos façam pesquisa sobre o conteúdo determinado. E assim no dia da aula, à medida em que ocorrer o sorteio das palavras, o aluno que tiver a palavra sorteada deverá além de marcar a palavra em sua cartela, explicar aquele conceito para o professor e os colegas de classe (Obs. Como mais de um aluno irá apresentar a mesma palavra na cartela, pode-se realizar a escolha ou sorteio entre eles de quem irá realizar a explicação para a classe). Vence o bingo aquele que primeiro completar a cartela, além de ser avaliado pela sua oralidade e desempenho durante a explicação. Outra sugestão é realizar o bingo através de grupo de estudantes, e assim à medida que acontece o sorteio das palavras, o grupo que possuir a palavra sorteada vem à frente da sala e explica o conceito.

$2^{\circ}$ ) Estratégia de verificação de aprendizagem ou revisão: No dia da aula em que o bingo será utilizado, no lugar de sortear as palavras, sortear frases com o conceito de cada palavra, para que os alunos identifiquem sobre qual palavra o professor está descrevendo. Então à medida que o professor lê em voz alta cada palavra, os alunos devem identificar aquele conceito, desta forma o professor pode verificar em quais conteúdos os alunos têm mais dificuldade de entendimento ou que já assimilaram, como também fazer uma revisão para uma avaliação escrita de forma diferenciada. Abaixo um modelo com um conjunto de palavras sobre as características do Reino Animalia. Exemplo de cartelas de bingos são disponibilizadas pelo site https://myfreebingocards.com/.

Exemplo de frases para o Bingo com conceitos sobre características do reino Animalia para o $2^{\circ}$ ano do Ensino Médio.

1. Animalia: nome dado ao reino que compreende seres vivos multicelulares, eucariontes e heterótrofos por digestão*.

2.Multicelulares: Organismos formados por diversas células.

3.Eucarionte: Célula que possui núcleo delimitado por membrana nuclear, além de diversas organelas membranosas.

4.Heterótrofos: organismos que não são capazes de produzir o próprio alimento, e por isso necessitam ingerir ou absorver moléculas orgânicas pré-formadas de outros seres vivos para obtenção de energia e síntese das biomoléculas de que necessitam.

5.Invertebrados: nome dado informalmente ao grupo de animais que não apresentam vértebras.

REnBio - Revista de Ensino de Biologia da SBEnBio - ISSN: 1982-1867 - vol. 13, n. 1, p. 120-140, 2020 
DOI: https://doi.org/10.46667/renbio.v13i1.312

6.Vertebrados: nome dado informalmente ao grupo de animais que apresentam vértebras.

7.Cladograma: é uma representação gráfica em forma de árvore ramificada, que mostra as relações filogenéticas entre seres vivos.

8.Protista flagelado heterótrofo: organismo que provavelmente foi o ancestral que deu origem aos animais e os fungos.

9.Fungos: grupo de seres vivos eucariontes que podem ser unicelulares ou pluricelulares, heterótrofos por absorção e que evolutivamente estão mais próximos dos animais.

10.Explosão do Cambriano: período geológico em que o registro fóssil mostra que surgiram praticamente todos os animais conhecidos atualmente.

11.Parazoários: grupo de animais que não apresentam tecidos.

12.Eumetazoários: grupo de animais que apresentam células organizadas em tecidos.

13.Poríferos: Filo dentro do reino Animália que reúne os primeiros animais que surgiram, e que são conhecidos popularmente como esponjas. O nome significa o portador de poros.

14.Ovíparos: são os animais cujo embrião se desenvolve dentro de um ovo em ambiente externo sem ligação com o corpo da mãe.

15. Ovovivíparos: são os animais cujo desenvolvimento embrionário ocorre dentro de ovos que se desenvolvem dentro do corpo materno

16. Vivíparos: são animais cujo embrião depende diretamente da mãe para sua nutrição, que ocorre por meio de trocas fisiológicas entre mãe e feto.

17.Protostômios: etiologicamente, do grego protos=primitivo, primeiro; stoma=boca,

são os animais em que o blastóporo permanece após a conclusão do desenvolvimento embrionário, com a função de boca.

18.Deuterostômios: etiologicamente, do grego deuteros, posterior + stoma, boca ,são os animais em que o blastóporo permanece após a conclusão do desenvolvimento embrionário, com a função de ânus.

19.Dipoblásticos: ou diblástico é a designação dada ao embrião que deriva de apenas dois folhetos embrionários, uma camada mais exterior, a ectoderme, e uma camada mais interior, a endoderme, não desenvolvendo a mesoderme.

20.Triploblásticos: ou triblástico é a designação dada ao embrião que deriva de três folhetos embrionários, uma camada mais exterior, a ectoderme, e uma camada mais interior, a endoderme, e a camada intermediária o mesoderme.

21.Acelomados: são animais que não apresentam celoma.

22.Celomados: são os animais que possuem uma cavidade revestida pelas células derivadas da mesoderme.

23.Psedocelomados: são os animais que possuem uma cavidade formada a partir da blastocele ;é delimitada em parte por tecidos derivados da mesoderme.

24.Esqueleto hidrostático: contribui na sustentação do corpo e da locomoção, interagindo com a musculatura, é também um meio para o transporte de gases, ou mesmo um espaço que permite o desenvolvimento de órgãos. 
DOI: https://doi.org/10.46667/renbio.v13i1.312

25.Simetria radial: é a simetria em que o corpo dos animais é dividido em alguns eixos, que passam através do corpo do animal, e as partes se repetem em volta deste eixo, e não apenas em um plano.

26.Simetrial bilateral: é a simetria em que o corpo do animal apresenta duas partes semelhantes, sendo dividido apenas por um único plano de simetria.

27.Metameria: é o nome dado a segmentação principal do corpo, própria de diversos grupos animais, numa série de metâmeros mais ou menos idênticos.

28.Reprodução sexuada: forma de reprodução dos animais que ocorre troca de material genético entre os gametas.

29.Cnidária: nome de um filo do Reino Animal. Possuem simetria radial, são diblásticos e vivem em ambientes aquáticos, sendo a grande maioria marinha, apresentam um tipo específico de célula em seus tentáculos, o cnidócito,e tem como um dos representantes as águas-vivas.

30.Platyhelminthes: nome de um filo do Reino Animal. Possuem simetria bilateral, nãosegmentados, protostômios, de corpo mole e relativamente simples, podem ser parasitas dos seres humanos, tem como um dos representantes as planárias.

31.Mollusca: nome de um filo do Reino Animal. Possuem o corpo mole e não-segmentado, muitas vezes dividido em cabeça (com os órgãos dos sentidos), um pé muscular e um manto que protege uma parte do corpo e que muitas vezes secreta uma concha e que tem como um dos representantes as lesmas.

32.Annelida: nome de um filo do Reino Animal. Possuem o corpo mole, alongado, cilíndrico e dividido em anéis, apresentando uma nítida segmentação, tem como um dos representantes as minhocas.

33.Nematoda: nome de um filo do Reino Animal. São animais triblásticos, protostômios, pseudocelomados. Seu corpo cilíndrico, alongado e não segmentado exibe simetria bilateral e tem como um dos representantes as lombrigas.

34.Arthopoda: nome de um filo do Reino Animal. Possuem exoesqueleto rígido e vários pares de apêndices articulados, cujo número varia de acordo com a classe.

35.Echinodermata: nome de um filo do Reino Animal. São deuterostômios exclusivamente marinhos e bentônicos, tem como um dos representantes as estrelas-do-mar.

36.Chordata: nome de um filo do Reino Animal .Constituem um filo dentro do reino Animalia que inclui Urocordados, Cefalocordados e Craniatas. Estes animais são caracterizados pela presença de uma simetria bilateral, notocorda, sistema digestório completo, um tubo nervoso dorsal, fendas branquiais e uma cauda pós-anal, em pelo menos uma fase de sua vida

- UTILIZAÇÃO DE QR CODES - Os alunos, do $7^{\circ}$ ano do Ensino Fundamental e do $2^{\circ}$ ano do Ensino Médio, podem ser divididos em grupos e então pesquisarem sobre determinado grupo animal. Após a realização da pesquisa, os alunos devem elaborar textos curtos e informativos para serem lidos no celular. Após a elaboração dos textos eles devem criar um QR Codes para ser impresso e exposto no entorno da escola. Essa informação ficará disponível para todos os alunos da escola que escanearem os códigos.

REnBio - Revista de Ensino de Biologia da SBEnBio - ISSN: 1982-1867 - vol. 13, n. 1, p. 120-140, 2020 
DOI: https://doi.org/10.46667/renbio.v13i1.312

- UTILIZAÇÃO DE PANFLETOS - A abordagem ecológica se faz necessário dentro do processo de ensino aprendizagem de Zoologia, para que o aluno tenha uma abordagem integral do conhecimento e não apenas de forma fragmentada. O uso de panfletos é uma estratégia que possibilita o exercício da criatividade e da escrita pelos alunos. $\mathrm{O}$ panfleto abaixo pode ser seguido como um modelo para que os alunos do $7^{\circ}$ ano do Ensino Fundamental escolham um animal vertebrado e outro invertebrado e através de pesquisas na internet e livros construam o seu panfleto.

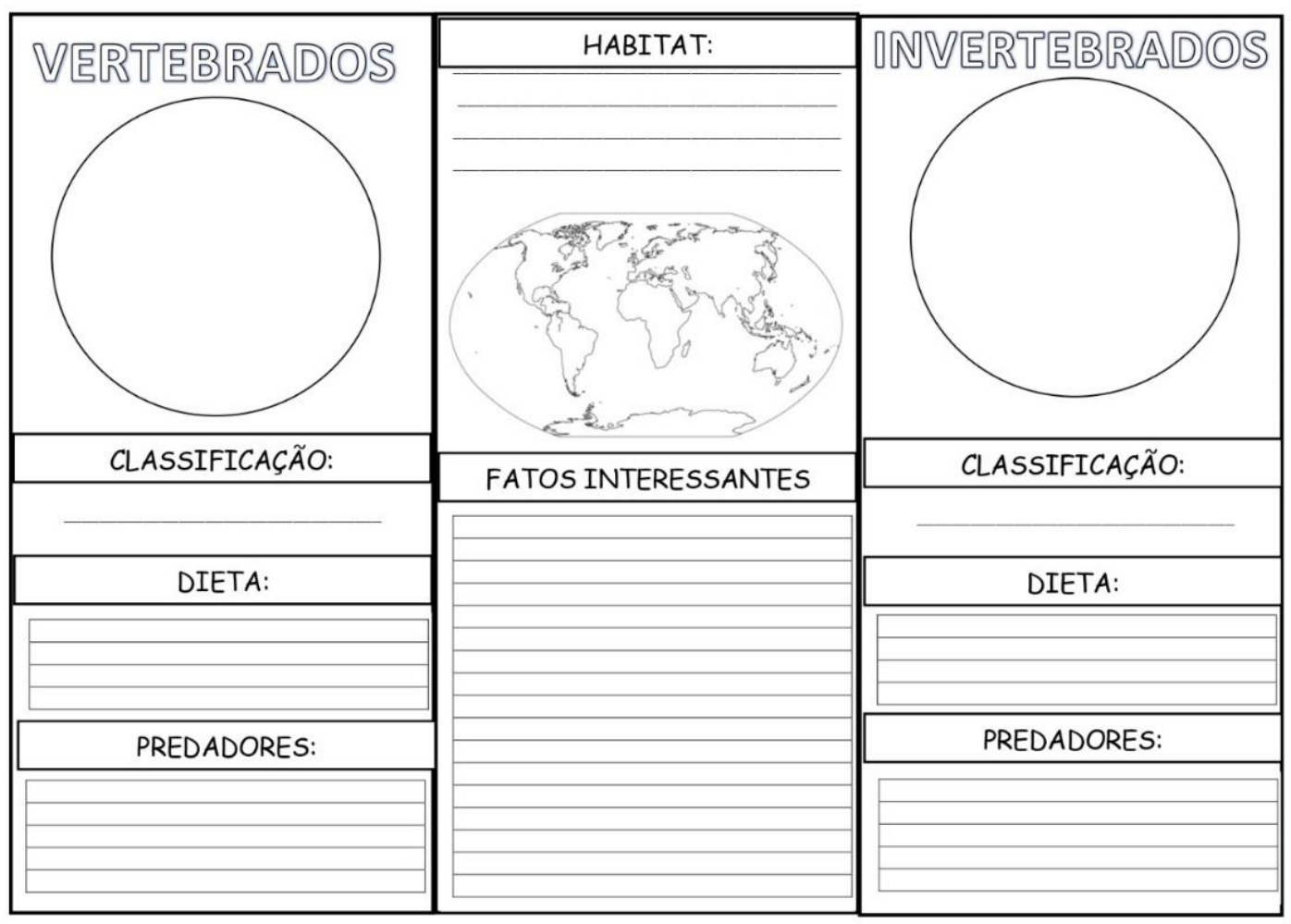


DOI: https://doi.org/10.46667/renbio.v13i1.312

- QUEBRA-CABEÇA - O uso de quebra-cabeça também é uma atividade que pode ser utilizada como uma estratégia de metodologia ativa para dar início a um conteúdo, ou como uma forma de estratégia de revisão na metodologia tradicional de ensino. Abaixo um exemplo de quebra cabeça para o $2^{\circ}$ ano do Ensino Médio.
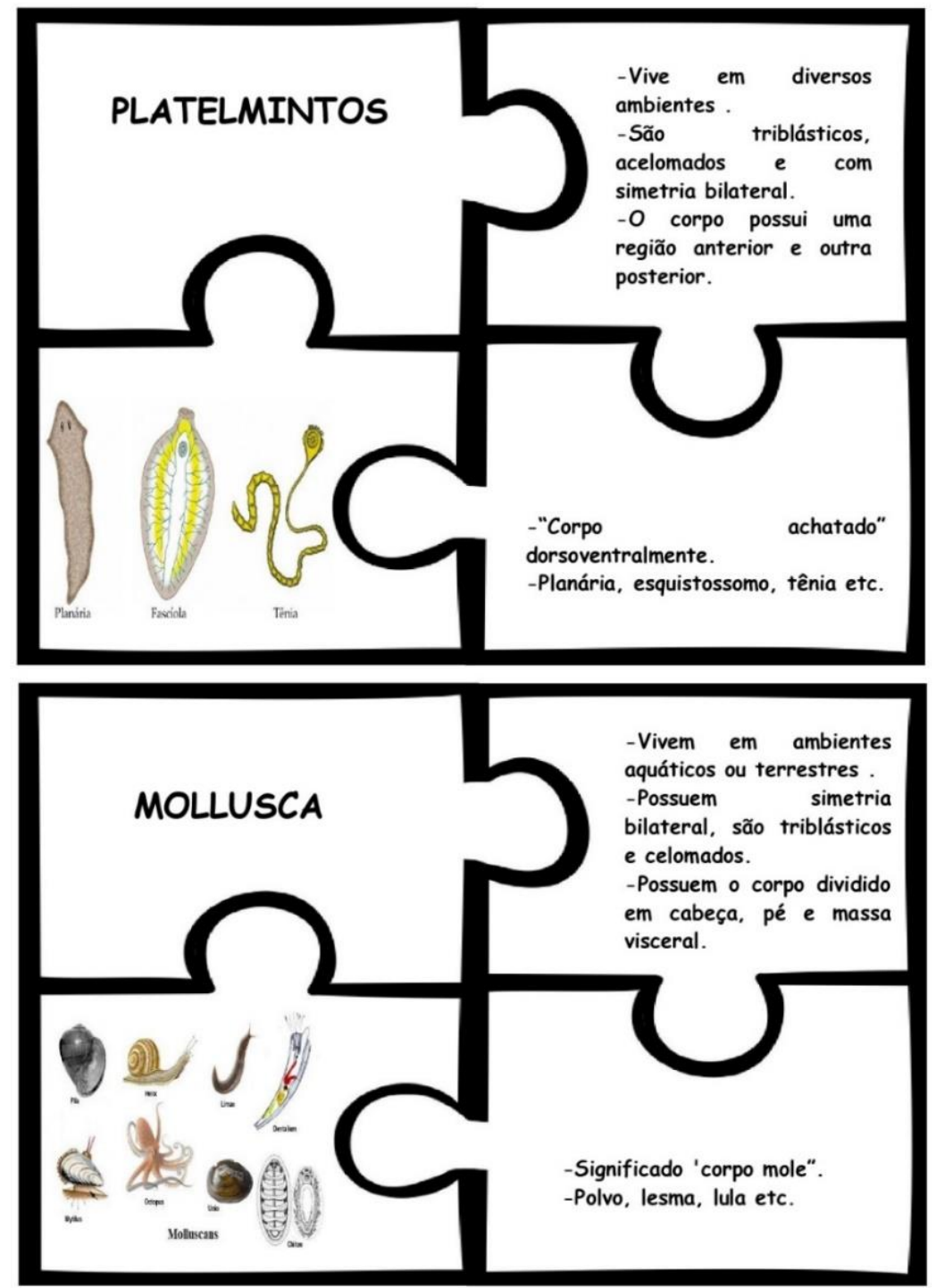

- UTILizAÇÃo DE CARTÃo DE PERGuntas E DESAFIOS - Os cartões de perguntas e desafios são ferramentas de ensino altamente motivadoras e eficazes que podem ser usadas em todo o currículo, não somente no ensino de Zoologia. Abaixo serão listadas algumas razões para o seu uso em sala de aula:

$\checkmark$ Os cartões de tarefas e desafios podem ser feitos para atingir objetivos específicos de aprendizado. Se os alunos possuem dificuldades em um determinado conteúdo 
DOI: https://doi.org/10.46667/renbio.v13i1.312

específico, você pode trabalhar e se concentrar neste conteúdo em si, além de ser uma ferramenta para preparação de avaliações.

$\checkmark$ Outra opção é permitir que alguns alunos respondam verbalmente. Dessa forma o professor estimula a oralidade da turma.

$\checkmark$ As cartas de perguntas e desafios são versáteis. Um único conjunto de cartões pode ser usado de várias maneiras; individualmente, em pares ou pequenos grupos, e até com toda a turma. Eles podem ser usados como parte de sua rotina diária, como enriquecimento, com jogos ou até mesmo como tarefa. Além disso, eles podem ser usados com qualquer faixa etária, além de auxiliar na economia de papel. Você pode imprimir, cortar e plastificar uma vez e assim usar por anos e então os alunos podem responder em papel de caderno ou em folhas brancas individuais.

Abaixo segue um exemplo de cartão de perguntas e desafios para o $2^{\circ}$ ano do Ensino Médio, traduzido e retirado do site em inglês https://gettingnerdywithmelandgerdy.com/ das professoras americanas Melissa Zaher e Gretchen Vikingson.
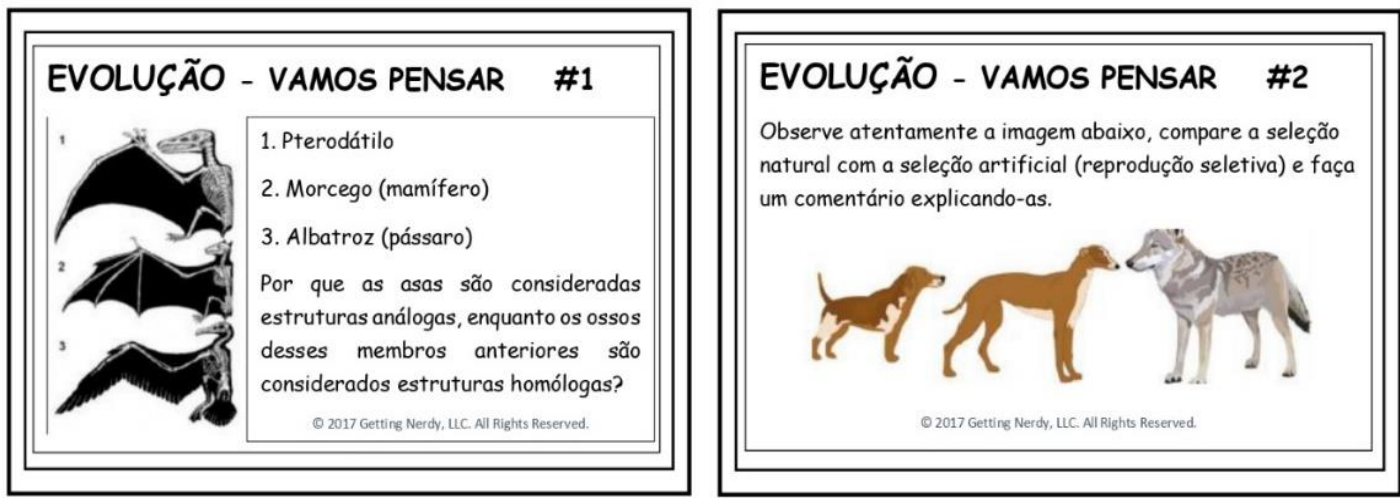

\section{EVOLUÇÃO - VAMOS PENSAR \#3}

Imagine um mundo onde os dinossauros ainda vagam pela Terra. Explique como esta existência afetaria sua vida hoje.

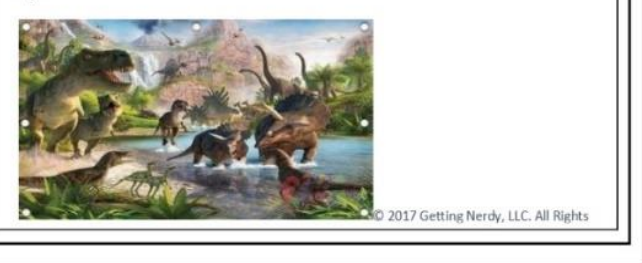

\section{EVOLUÇÃO - VAMOS PENSAR \#4}

Faça um desenho do que você acha que este dinossauro fossilizado seria na vida real.

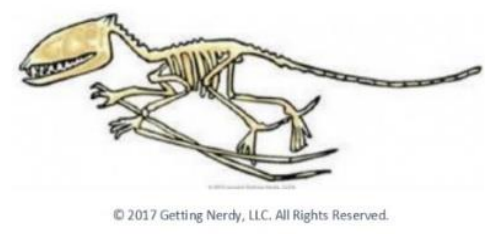

- UTILIZAÇÃO DE MODELOS DIDÁTICOS - Durante o ensino de Zoologia uma das grandes dificuldades encontradas pelos professores de Biologia, é a falta de recursos didáticos que facilitem a assimilação dos conteúdos pelos estudantes. A utilização de modelos didáticos para o ensino de Zoologia permite a visualização de uma estrutura em três dimensões, facilitando o processo de ensino e aprendizagem nos diferentes níveis de ensino, e muitas das vezes os animais a serem estudados não são familiares 
DOI: https://doi.org/10.46667/renbio.v13i1.312

para os estudantes, portanto a visualização é fundamental, além de despertar o interesse dos estudantes. Os modelos didáticos com custo mais acessível para escolas públicas são representações confeccionadas de biscuit e outros materiais alternativos que podem ser produzidos pelos próprios alunos do $7^{\circ}$ ano do Ensino Fundamental e do $2^{\circ}$ ano do Ensino Médio, ou serem adquiridos em lojas na internet pela escola ou professor.

- INSTAGRAM - No ensino de Zoologia o professor pode utilizar como tática para alunos do $7^{\circ}$ ano do Ensino Fundamental e $2^{\circ}$ ano do Ensino Médio, o aplicativo de celular Instagram das seguintes formas:

$>$ Promover um quiz sobre a Zoologia para sondar a aprendizagem.

$>$ Postar atualidades e notícias pedindo que os alunos façam comentários.

$>$ Produzir aulas para que os alunos possam acessar sempre que necessário.

$>$ Postar mídias de curta metragem, e pedir os alunos para comentarem.

O aluno poderá ser investigador e a até mesmo postar descobertas, e imagens de animais da região.

\section{Discussão}

Os resultados encontrados neste trabalho sobre o perfil dos professores de Ciências e Biologia da SRE de Caratinga, demonstram que a maioria é do sexo feminino e predomínio da faixa etária entre 30 e 45 anos, dados esses que são equivalentes ao reportado pela pesquisa da OCDE (2015/2018), dissertação de mestrado de OLIVEIRA (2017), de SANTOS (2010) e na pesquisa de GATTI e BARRETO (2009). A distribuição etária dos professores reflete a dinâmica das contratações dos profissionais e demonstra que o Brasil possui professores mais jovens, comparados a outros países membros da OCDE (INEP, 2018). A maior parte dos professores possui de 11 a 15 anos de experiência em magistério, corroborando ao constatado pela OCDE em que mais de $86 \%$ dos professores brasileiros de Ciências possuem mais de 5 anos de experiência.

Todos os professores possuem curso superior, e, em sua maioria, tal formação foi adquirida principalmente em universidades privadas da cidade de Ipatinga (UNIILESTE), Caratinga (UNEC) e Governador Valadares (UNIVALE). Esta alta porcentagem de licenciados em IES privadas pode ser devido á longa distância de IES pública com curso de licenciatura em Ciências Biológicas do local de moradia dos alunos universitários. Em 2006 a quantidade de alunos matriculados nas instituições privadas era de $57 \%$ em relação ás escolas públicas (GATTI e BARRETO 2009).

Em relação ao ensino de Zoologia, a maioria dos professores associaram de forma errônea o conteúdo científico com a prática didática-pedagógica, e entendem que ao cursarem as disciplinas específicas de Zoologia, estas, os capacitam a lecioná-la, OLIVEIRA (2017) e SANTOS (2010) relataram situação semelhante em suas respectivas pesquisas. Os resultados também demonstraram que a maioria dos professores confundem metodologias com as estratégias de ensino e que ainda há um predomínio das metodologias ditas tradicionais. 
DOI: https://doi.org/10.46667/renbio.v13i1.312

Segundo GATTI e BARRETO (2009), ainda que a carga horária aplicada a área educacional dos cursos de licenciaturas de Ciências e Biologia do Brasil seja significativa, admitem que falta nos cursos de formação de licenciatura, uma maior articulação entre a prática-teórica e prática pedagógica.

Em 2010, GATTI apontou alguns problemas nos cursos de Licenciaturas em Língua Portuguesa, Matemática e Ciências Biológicas no Brasil, dentre eles destaca-se a inexistência de um núcleo compartilhado de disciplinas da área de formação para a docência, conteúdos heterogêneos nas disciplinas de Didática, Metodologia e Práticas de Ensino e número reduzido de disciplinas teóricas da área de Educação. Apontou ainda, que nas matrizes curriculares desses cursos as disciplinas aplicadas são mais teóricas que práticas. Concluiu que existe ausência de um eixo formativo claro para a docência e pulverização na formação dos licenciados, indicando frágil preparação para o exercício do magistério na educação básica. De acordo com RICHTER et al., 2015, prevalece uma concepção Técnica no Ensino de Zoologia, cuja visão é influenciada por princípios de ensino instrumentalizado resultando em falta de autonomia do professor sobre a sua própria prática. Ressaltam que é função estritamente do professor de Ciências e Biologia, significar e difundir os saberes construídos historicamente, para que os alunos construam uma compreensão dos fatos naturais, sob uma visão crítica dos vários processos que permeiam os seres vivos e suas relações.

Os docentes reconhecem que o uso de aulas práticas é uma estratégia eficiente para o processo de ensino aprendizagem, porém, elas são utilizadas somente por $50 \%$ dos professores e os que não utilizam, alegaram que sua realização é dificultada por falta de recursos materiais, espaços apropriados, uma vez que a maioria das escolas não possui laboratório. Segundo WAISELFISZ (2009), no Brasil as deficiências relacionadas a laboratórios (recursos, equipamentos, técnicos) afeta acima de $90 \%$ das escolas brasileiras, tal deficiência é muito mais elevada que em qualquer país membro da OCDE organização responsável pelo PISA.

As aulas práticas são ferramentas importantes no ensino, pois permitem aos estudantes observarem que as leis da Ciência não são imutáveis e desmistificam a ideia de que Ciência só pode ser desenvolvida em laboratórios bem aparelhados (VASCONCELOS et al., 2002). NEVES e SCHWANTES (2019) apresentaram uma abordagem metodológica aplicada ao ensino de Zoologia unindo duas estratégias didáticas, educar pela pesquisa e análise dos casos investigativos. No processo, foi abordado o método científico no espaço escolar, o qual permitiu aos estudantes vivenciarem e engajarem-se nas práticas sociais da cultura científica. Elas relataram que durante sua aplicação os estudantes passaram a desenvolver a autonomia, a reflexão, a liberdade de expressão e o raciocínio científico, bem como, favoreceu a interdisciplinaridade e a contextualização, valorizando a fauna brasileira.

As principais opiniões e sugestões feitas pelos professores de Ciências e Biologia, indicam a construção de laboratórios (ou melhoria das estruturas dos laboratórios já existentes) e aquisição de recursos didáticos como fundamental para a melhoria do Ensino de Zoologia. Corroborando a sugestão dos professores, KRASILCHIK, 2004 afirma que ouvir 
DOI: https://doi.org/10.46667/renbio.v13i1.312

falar de um organismo em sala de aula é, em geral, muito menos interessante e eficiente do que ver diretamente a realidade, o que justifica a inclusão das excursões, demonstrações e aulas práticas. Assim, para que as aulas de conteúdo zoológico nas disciplinas de Biologia e Ciências se tornem mais atrativas, é importante o desenvolvimento de atividades práticas, possibilitando aos alunos contato direto com os organismos estudados nas aulas teóricas (SANTOS e GONDIM, 2013). As aulas de campo, ou seja, o uso de espaço não-formal, também foi apontado, mas em menor porcentagem, e pode ser justificado por dificuldade em conseguir transporte gratuito, limitação e insegurança do professor em gerenciar a turma fora da sala de aula e imensa burocracia (autorizações dos pais, parceria com os demais professores para cederem a aula e acompanharem a atividade).

Todos os professores se orientam pelo livro didático, mas alguns afirmaram que o livro didático não favorece o ensino-aprendizagem de Biologia. Eles sugerem que os livros didáticos apresentem maior contextualização e atividades diferenciadas, porém, um único professor manifestou que é necessário ter parcimônia e maior critério durante o processo de escolha do mesmo, pois entende que o livro didático é importante para o processo ensino -aprendizagem de Zoologia. A contextualização de conceitos zoológicos também é limitada no Parâmetro Curricular Nacional (BRASIL, 1998) e neste documento verifica-se abordagem de temas sobre classificação, anatomia e fisiologia comparadas sem considerar a interação dos organismos entre si e sua associação com o ambiente. Segundo VASCONCELOS e SOUTO (2003) o livro de Ciências é uma ferramenta pedagógica de suma importância para o ensino, e cumpre uma função extra de aplicar e estimular o método científico, porém, atentam para o fato de que a maioria dos livros disponíveis no mercado brasileiro, dispõe os conteúdos de forma linear e fragmentada do conhecimento, limitando uma perspectiva interdisciplinar.

Os resultados desta pesquisa demonstraram, dentre outros achados, que o livro didático é o guia dos professores, posto isto, consideramos de suma importância agregar e divulgar diferentes recursos didáticos aos docentes para colaborar com o processo de ensinoaprendizagem da Zoologia nas escolas em que essa pesquisa foi realizada e pretendemos que se estenda a todas as escolas pertencentes à SRE de Caratinga.

\section{Conclusão}

As metodologias e recursos didáticos utilizados pelos professores do sétimo ano do Ensino Fundamental e do segundo ano do Ensino Médio para o ensino de Zoologia das escolas estaduais na Superintendência Regional de Ensino de Caratinga são principalmente aulas expositivas simples e dialogada, pautada na metodologia tradicional de ensino com utilização prioritariamente de livros didáticos e pouca relação eco evolutiva das espécies animais, embora, metade dos professores participantes da pesquisa também utilize aulas práticas e poucos utilizam atividades de campo. Há o predomínio da forma tradicional de avaliação da aprendizagem dos estudantes no ensino de Zoologia que é feita através de provas teóricas escritas individuais. Os professores apontaram que laboratórios e aquisição de material didático são importantes para a melhoria do ensino, logo, acreditamos que o material que 
DOI: https://doi.org/10.46667/renbio.v13i1.312

desenvolvemos para esse fim, com abordagem lúdica, investigativa e possível de ser realizado em sala de aula, colabore significativamente para o processo ensino-aprendizagem e futuramente contribua para melhorias no ensino de Zoologia na SRE de Caratinga.

\section{Referências}

ANTUNES Celso. Novas maneiras de ensinar, novas formas de aprender. Porto Alegre: Artmed, 2002. p. 51-59.

AZEVEDO, H. J. C. C. Introdução ao ensino de zoologia. Goiânia, GO: Espaço Acadêmico, 2019.

AZEVEDO, M. E. O.; DE OLIVEIRA, M. C. A.; LIMA, D. C. A zoologia no ensino médio de escolas estaduais do município de Itapipoca, Ceará. Revista da SBEnBio, v.9, p. 61436154, 2016.

BARDIN, L. Análise de conteúdo. 4. ed. Lisboa: Edições 70, 2009.

BASTOS JUNIOR, P. S. Metodologias e estratégias para o ensino de Zoologia. 2013. Trabalho de conclusão de curso (Licenciatura em Ciências Naturais) - Universidade de Brasília, Planaltina, 2013.

BRASIL. Secretaria de Educação Fundamental. Parâmetros Curriculares Nacionais: ciências naturais. Brasília, DF: MEC/SEF, 1998.

CAMPOS, C. J. C. Método de análise de conteúdo: ferramenta para a análise de conteúdo de dados qualitativos no campo da saúde. Revista Brasileira de enfermagem, v.57, n.5, p.611614, 2004.

CRESPO, A. A. Estatística fácil. 19. ed. São Paulo: Saraiva, 2009.

DIAS, M.G; SESSA. P. Ensino de zoologia em foco: interações e atividades investigativas. In: CONGRESSO INTERNACIONAL SOBRE INVESTIGACION EM DIDACTICA DE LAS CIÊNCIAS, 10., 2017. Anais...Sevilla, Espanha, 2017. p.5493-5497. ISSN (DIGITAL): 2174-6486. Disponível em: https://ddd.uab.cat/pub/edlc/edlc_a2017nEXTRA/123_Ensino_de_Zoologia_em_foco_interacoes_e_atividades_investigativas.pdf

FERREIRA, F.S; BRITO, S.V.; RIBEIRO, S.C.; SALES, D.L.; ALMEIDA, W.O. A zoologia e a botânica do ensino médio sob uma perspectiva evolutiva: uma alternativa de ensino para o estudo da biodiversidade. Cad. Cult. Ciênc, v. 2, n.1, p.58-66, 2008.

GATTI, B.A.; BARRETO, E.S.S. Professores: aspectos de sua profissionalização, formação e valorização social. Brasília, DF: UNESCO, 2009. (Relatório de Pesquisa)

GATTI, B. A. Formação de professores no Brasil: características e problemas. Educação \& Sociedade, v.31, n.113, p. 1355-1379, 2010.

KRASILCHIK, M. Prática de ensino de biologia. Universidade de São Paulo: EDUSP, 2004. 
DOI: https://doi.org/10.46667/renbio.v13i1.312

LOPES, R. W.; FERREIRA, M. J. M.; STEVAUX, M. N. Proposta pedagógica para o ensino médio: filogenia de animais. Revista Solta a Voz, v. 18, n. 2, 2007.

MINISTÉRIO DA EDUCAÇÃO. Parâmetros Curriculares Nacionais: ciências da natureza e suas tecnologias (PCN), Brasília: Secretaria da Educação Básica, 1997.

MINISTÉRIO DA EDUCAÇÃO. Letramento científico. Disponível em: http://download.inep.gov.br/download/internacional/pisa/2010/letramento_cientifico.pdf .

MINISTÉRIO DA EDUCAÇÃO. Programa Nacional do Livro didático. Disponível em: http://www.fnde.gov.br/programas/programas-do-livro/pnld/guia-do-livrodidatico/item/11986-escolha-pnld-2019

NEVES, K. R. DAS; SCHWANTES, L. Ensino de zoologia por desafios de observação: o método científico como instrumento de aprendizagem. REnBio - Revista de Ensino de Biologia da SBEnBio, v. 12, n.2, p. 188-206, 2019. ISSN: 1982-1867.

OCDE. Principais dados do Brasil no Education at a Glance 2015. Disponível em: http://www.oecd.org/education/school/TALIS-2013-country-note-Brazil-Portuguese.pdf., 2015.

OCDE. Principais dados do Brasil no Education at a Glance 2018. Disponível em: http://download.inep.gov.br/acoes_internacionais/pesquisa_talis/resultados/2018/relatorio_na cional_talis2018.pdf.

OLIVEIRA, C. DE. A Zoologia nas escolas: percursos do ensino de zoologia em escolas da rede pública no município de Aracaju/SE. 2017. Dissertação (Mestrado Profissional em Ensino de Ciências Naturais e Matemática) - Universidade Federal do São Cristóvão, Sergipe, 2017.

PISA: Informe de resultados da pisa, 2015. Disponível em: http://download.inep.gov.br/acoes_internacionais/pisa/resultados/2015/pisa_satisfacao_do_pr ofessor_de_ciencias.pdf., 2015.

PRINCIPAIS dados do Brasil no Education at a Glance, 2013. Disponível em: https://www.oecd.org/brazil/Education-at-a-glance-2015-Brazil-in-Portuguese.pdf, 2013.

SANTANA, D. R.; SOUZA NETO L. G.; DA SILVA, L. A. M. Uma proposta para construção de tirinha para o Ensino de Zoologia: Idealização e Elaboração. Revista Ciências \& Ideias, v.11, n.1, p. 298-322, 2020.

SANTOS, S. C. S. Diagnóstico e possibilidades para o ensino de zoologia em Manaus/AM. 2010. Dissertação (Mestrado Profissional em Ensino de Ciências) - Escola Normal Superior da Universidade do Estado do Amazonas, Manaus, 2010.

SANTOS, S. C. S.; FACHÍN-TÉRAN, A. Possibilidade do uso de analogia e metáfora no processo de ensino-aprendizagem no Ensino de Zoologia no $7^{\circ}$ ano do Ensino Fundamental. In: CONGRESSO NORTE NORDESTE DE ENSINO DE CIÊNCIAS E MATEMÁTICA. Anais...Boa Vista: UERR, 2009. 
DOI: https://doi.org/10.46667/renbio.v13i1.312

SANTOS, S. C. S.; FACHÍN-TÉRAN, A. Condições de ensino em zoologia no nível fundamental: o caso das escolas municipais de Manaus, AM. Revista Amazônica de Ensino de Ciências, Manaus, 2013. v.6, n.10, p. 1-18.

SANTOS, L. A. S.; GONDIM, M. J. C. Ações para a organização de uma coleção didática de zoologia em uma escola de Uberlândia, MG. Rev. Ciênc. Ext. v.9, n.2, p.19-27, 2013.

SANTOS, A. B.; GUIMARÃES, C. R. P. A utilização de jogos como recurso didático no ensino de zoologia. Rev. Elétrons. Investig. Educ. Cienc. v.5 n.2, 2010.

VASCONCELOS, I; PRAIA, J.F; Almeida, L.S. Theory of learninf and the teaching-learning of sciences-from instruction to apprenticeship. Psicologia Escolar e Educacional, Campinas, v.7. n. 1, 2002.

VASCONCELOS, S.; SOUTO, E. O livro didático de Ciências no Ensino Fundamental proposta de critérios para análise do conteúdo zoológico. Ciência \& Educação, 2003. v. 9, n. 1, p. 93-104.

WAISELFISZ, J. J. O ensino das ciências no Brasil e o PISA. São Paulo: Sangari do Brasil, 2009. 